\title{
Prevention of rocuronium injection pain
}

\author{
Sungsik Park \\ Department of Anesthesiology and Pain Medicine, Kyungpook National University School of Medicine, Daegu, Korea
}

The introduction of rocuronium bromide to the anesthetic field has led to its replacement of succinylcholine for rapidsequence intubation because of its rapid onset time and intermediate duration. Rocuronium is an especially good choice for children because it avoids the complications of succinylcholine; however, injection pain or withdrawal movement (IPWM) has been reported [1]. IPWM is characterized by sudden flexion of the wrist and arm after rocuronium infusion, lasting 10-20 seconds [2]. The incidence of rocuronium-induced IPWM is reportedly $50-80 \%$.

Some authors have argued against the necessity of alleviating IPWM based on the lack of convincing data regarding negative patient outcomes caused by IPWM [3]. However, pain on injection and other stressful stimulation during anesthetic induction may cause bronchospasm or myocardial infarction [4,5]. Additionally, a case of pulmonary aspiration caused by rocuroniuminduced generalized spontaneous movements has been reported [6]. These findings highlight the importance of alleviating IPWM caused by rocuronium.

In an article published in this issue of the Korean Journal of Anesthesiology, Na et al. [7] demonstrate the efficacy of sevoflurane combined with remifentanil against withdrawal movement associated with rocuronium injection in children. The incidence and severity of IPWM are higher in children than in adults [8]. The high incidence of generalized movements in children could cause injury or dislodgement of the venous catheter. Thus, it is more important to prevent IPWM in children than in adults.

According to $\mathrm{Na}$ et al. [7], 54 and $20 \%$ of children who received 2.0 vol\% sevoflurane exhibited withdrawal movement and generalized movement respectively; these rates were similar among children who received remifentanil (57 and 17\%, respectively). However, when 2.0 vol\% sevoflurane was combined with remifentanil at $0.5 \mu \mathrm{g} / \mathrm{kg}$, the incidence of withdrawal move- ment decreased to $17 \%$ while all generalized movement ceased.

In two recently published studies $[9,10]$, the $50 \%$ effective end-tidal concentration of sevoflurane (ETsev) was 2.4 vol\% in adults and 2.9 vol\% in children. In those same studies, the 95\% effective ETsev was 3.0-3.5 vol\% in adults and $4.3 \mathrm{vol} \%$ in children. The 2.0 vol\% sevoflurane reported by $\mathrm{Na}$ et al. [7] was relatively lower concentration to prevention of IPWM.

The remifentanil dose used by $\mathrm{Na}$ et al. [7] was also relatively lower than that used in other studies. There was no withdrawal movement in $77 \%$ of patients treated with $1 \mu \mathrm{g} / \mathrm{kg}$ of remifentanil [11]. Kim et al. [12] reported that remifentanil at $1.0 \mu \mathrm{g} /$ $\mathrm{kg}$ prevented IPWM after rocuronium more effectively than did remifentanil at $0.5 \mu \mathrm{g} / \mathrm{kg}$. O'Hare et al. [13] reported that remifentanil at $0.5 \mu \mathrm{g} / \mathrm{kg}$ did not adequately control the hemodynamic changes that occurred after intubation. However, higher doses could result in side effects. Remifentanil at $1.0 \mu \mathrm{g} /$ $\mathrm{kg}$ caused coughing in $14 \%$ of patients [11].

Many types of drugs have been investigated for the prevention of IPWM [14,15]; however, few studies have attempted to evaluate the combined effects of more than two drugs on IPWM after rocuronium administration. $\mathrm{Na}$ et al. [7] evaluated the effect of a combination of sevoflurane and remifentanil. Separately administered low doses of sevoflurane and remifentanil did not prevent IPWM effectively after rocuronium administration. However, when these drugs were combined the effect was comparable with that of higher doses. Additionally, combined treatment could minimize the side effects of higher doses of sevoflurane or remifentanil.

In conclusion, the combination of an inhalation agent with an intravenous agent to prevent IPWM caused by rocuronium is a proper approach, especially for children, who require rapid airway management.

Corresponding author: Sungsik Park, M.D., Ph.D., Department of Anesthesiology and Pain Medicine, Kyungpook National University School of Medicine, 130, Dongdeok-ro, Jung-gu, Daegu 700-721, Korea. Tel: 82-53-420-5877, Fax: 82-53-426-2760, E-mail: sspark@knu.ac.kr (c) This is an open-access article distributed under the terms of the Creative Commons Attribution Non-Commercial License (http:// creativecommons.org/licenses/by-nc/3.0/), which permits unrestricted non-commercial use, distribution, and reproduction in any medium, provided the original work is properly cited. 


\section{References}

1. Morthy SS, Dierdorf SF. Pain on injection of rocuronium bromide. Anesth Analg 1995; 80: 1067.

2. Borgeat A, Kwiatkowski D. Spontaneous movements associated with rocuronium: is pain on injection the cause? Br J Anaesth 1997; 79: 382-3.

3. Mencke T, Beerhalter U, Fuchs-Buder T. Spontaneous movements, local reactions and pain on injection of rocuronium. A comparison between female and male patients. Acta Anaesthesiol Scand 2001; 45: 1002-5.

4. Morishima T, Sobue K, Arima H, Tanaka S, So M, Ando H, et al. Profound pain due to propofol injection triggered myocardial ischemia in a patient with a suspected pheochromocytoma. Anesth Analg 2003; 96: 631.

5. Zeidan A. Profound pain due to propofol injection triggered severe bronchospasm in a smoker-A case report. Middle East J Anaesthesiol 2006; 18: 939-42.

6. Lui JT, Huang SJ, Yang CY, Hsu JC, Lui PW. Rocuronium-induced generalized spontaneous movements cause pulmonary aspiration. Chang Gung Med J 2002; 25: 617-20.

7. Na YC, Lee HG, Lee SH, Jang EA, Yoon MH. The efficacy of sevolflurane inhalation alone, or its combination with intravenous remifentanil, against withdrawal movements on rocuronium injection in children. Korean J Anesthesiol 2014; 67: 373-7.

8. Shevchenko Y, Jocson JC, McRae VA, Stayer SA, Schwartz RE, Rehman M, et al. The use of lidocaine for preventing the withdrawal associated with the injection of rocuronium in children and adolescents. Anesth Analg 1999; 88: 746-8.

9. Yeom JH, Kim KH, Choe GH, Lee JM. End-tidal concentration of sevoflurane for reducing rocuronium-induced withdrawal reactions in adult patients: a comparison between male and female patients. Korean J Anesthesiol 2014; 66: 439-43.

10. Yeom JH, Kim YO, Lee JM, Jeon WJ. End-tidal concentration of sevoflurane for preventing rocuronium-induced withdrawal of the arm in pediatric patients. Korean J Anesthesiol 2014; 66: 274-7.

11. Kim JY, Kim JY, Kim YB, Kwak HJ. Pretreatment with remifentanil to prevent withdrawal after rocuronium in children. Br J Anaesth 2007; 98: 120-3.

12. Kim JY, Kwak HJ, Kim JY, Park KS, Song JS. Prevention of rocuronium-induced withdrawal movement in children: a comparison of remifentanil with alfentanil. Paediatr Anaesth 2008; 18: 245-50.

13. O'Hare R, McAtamney D, Mirakhur RK, Hughes D, Carabine U. Bolus dose remifentanil for control of haemodynamic response to tracheal intubation during rapid sequence induction of anaesthesia. Br J Anaesth 1999; 82: 283-5.

14. Choi GJ, Lee S, Lee JH, Park SG, Kang H. Pharmacological and non-pharmacological intervention for rocuronium-induced withdrawal movement in the Korean population: a meta-analysis of 41 studies including 4,742 subjects. Korean J Anesthesiol 2014; 66: 419-32.

15. Kwak HJ, Kim JY, Kim YB, Min SK, Moon BK, Kim JY. Pharmacological prevention of rocuronium-induced injection pain or withdrawal movements: a meta analysis. J Anesth 2013; 27: 742-9. 